\title{
The International Takeoff of New Products: The Role of Economics, Culture, and Country Innovativeness
}

\author{
Gerard J. Tellis • Stefan Stremersch • Eden Yin \\ Marshall School of Business, The University of Southern California, P.O. Box 90089-1421, \\ Los Angeles, California 90089-1421 \\ Erasmus University Rotterdam, P.O. Box 1738, Burg. Oudlaan 50, \\ 3000 DR Rotterdam, The Netherlands \\ Judge Institute, Cambridge University, Trumpington Street, Cambridge CB2 1AG, UK \\ tellis@usc.edu・stremersch@few.eur.nl・e.yin@jims.cam.ac.uk
}

Sales takeoff is vitally important for the management of new products. Limited prior Sresearch on this phenomenon covers only the United States. This study addresses the following questions about takeoff in Europe:

1) Does takeoff occur as distinctly in other countries, as it does in the United States?

2) Do different categories and countries have consistently different times-to-takeoff?

3) What economic and cultural factors explain the intercountry differences?

4) Should managers use a sprinkler or waterfall strategy for the introduction of new products across countries?

We gathered data on 137 new products across 10 categories and 16 European countries.

We adapted the threshold rule for identifying takeoff (Golder and Tellis 1997) to this multinational context. We specify a parametric hazard model to answer the questions above. The major results are as follows:

1) Sales of most new products display a distinct takeoff in various European countries, at an average of six years after introduction.

2) The time-to-takeoff varies substantially across countries and categories. It is four times shorter for entertainment products than for kitchen and laundry appliances. It is almost half as long in Scandinavian countries as in Mediterranean countries.

3) While culture partially explains intercountry differences in time-to-takeoff, economic factors are neither strong nor robust explanatory factors.

4) These results suggest distinct advantages to a waterfall strategy for introducing products in international markets.

(International New Product Growth; New Product Takeoff; New Product Growth; International Diffusion; Diffusion of Innovations)

\section{Introduction}

New products do not grow into maturity at a steady rate. Rather, their sales pattern is marked by a long introduction period when sales linger at low levels. At a certain point in time, the new product breaks into rapid growth, associated with a huge jump in sales. Academic literature and the business press refer to this point as the takeoff in sales. It is the point of transition between the introduction and growth stage of a new product. The time-to-takeoff is the duration of the 
introductory stage or the period from the introduction to the takeoff.

The takeoff of new products is a vitally important phenomenon in the management of new products for several reasons. First, growth rate in sales at takeoff may exceed $400 \%$ (Golder and Tellis 1997). Such rapid growth requires extensive resources in terms of advertising, sales staff, manufacturing, distribution, and inventory support. Second, many new product managers are under extensive pressure to pull the plug on new products that show sluggish sales. However, research shows that the introduction period may be quite long and variable. Knowing the likelihood and timing of the takeoff of a new product helps to withstand the pressure to pull the plug and preempt premature cancellation of promising new products. Third, takeoff is often a signal of the mass adoption of a product and its ultimate commercial success. Knowing the impact of company decisions on the likelihood and timing of takeoff is important for effectively managing such success. Fourth, the introduction and takeoff of new products across various countries are critical events in international marketing strategies. This issue has gained importance with increasing globalization and unification among countries within trade zones (EU, NAFTA, GATT, etc.). Knowing how takeoff varies across countries is important for designing effective international strategies.

Recently, Agarwal and Bayus (2002) and Golder and Tellis (1997) modeled the takeoff of consumer durables in the United States. These studies raise a number of questions about takeoff in the international realm, which we attempt to address in the context of Europe:

- Does the phenomenon of takeoff occur as distinctly in other countries, especially in European countries, as it does in the United States?

- Do different categories and countries have consistently different times-of-takeoff?

- What economic and cultural factors explain the intercountry differences?

- Should managers use a sprinkler or waterfall strategy for the introduction of new products across countries?

The only relevant literature on this topic occurs in the related field of diffusion modeling. Although this literature is extensive, with more than a hundred studies (Mahajan et al. 1990), only a few of these studies address the international diffusion of new products. Most of them examine how the parameters of the Bass diffusion model vary by country (Ganesh et al. 1997, Gatignon et al. 1989, Heeler and Hustad 1980, Helsen et al. 1993, Putsis and Sen 2001, Takada and Jain 1991, and Talukadar et al. 2001). Putsis et al. (1997) model the influence of "mixing" between countries on cross-country diffusion patterns. Dekimpe et al. (2000) examine the sequential adoption of a technological innovation by various countries. None of these studies addresses the takeoff of new products across multiple countries.

The present study focuses on the variation in timeto-takeoff of 10 new consumer durables across 16 European countries (see Figure 1 for examples). As such, this is the most extensive study ever conducted on the growth of new products in Europe. Besides country-specific differences, the study also examines how underlying economic and cultural characteristics explain the variation in time-to-takeoff across countries.

We chose Europe as a domain of analysis for two reasons. First, European countries have a relatively long history of developed capitalist markets. As such, data on new product introductions are available in these countries, though neither complete nor easy to obtain. Second, Europe has a long post-WW II history of unification toward a single market, through institutes such as the European Council, the Benelux, the West-European Union, the North American Treaty Organization, the Organization for Economic Cooperation and Development, the European Free Trade Association, The European Union, and the European Monetary Union. ${ }^{1}$ With the introduction of a single European currency (the EURO), the culmination of the unification movement, there is a growing perception among some economists and non-Europeans that the western half of the continent constitutes a single European market. Yet at the same time, these countries differ substantially in economic strength and

\footnotetext{
${ }^{1}$ These institutions have changed names over the course of their existence; we use the most recent ones.
} 
Figure 1 Illustration of Takeoff in Selected Countries
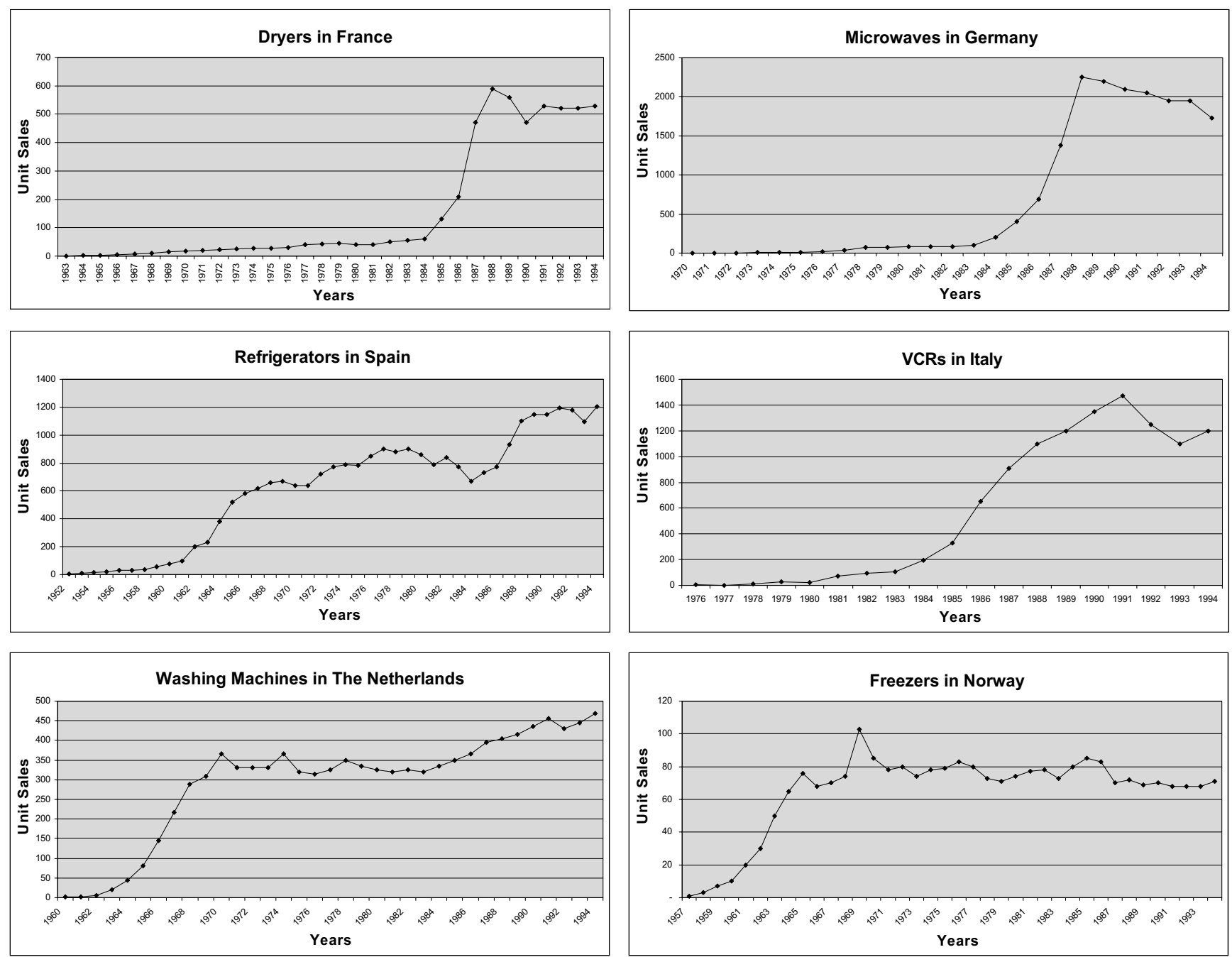

cultural identity. Thus there is an equally strong perception among nationalists and Europeans that these countries have distinct market identities. The takeoff of new products is an important context in which to test some of these rival perceptions.

This paper is organized as follows. The second section presents the model and research hypotheses. The third section explains the data. The fourth section presents the results. The final section discusses the findings, implications, and limitations.

\section{Modeling International Takeoff}

As Golder and Tellis (1997) explain, takeoff is a timedependent binary event that is best modeled by the

hazard model. However, unlike Golder and Tellis (1997), we use a parametric hazard model rather than the proportional hazard model that they use. We modify the threshold rule they use and also use raters to identify the takeoff. We explain our approach below in two parts: model development, and conceptual framework and hypotheses.

\section{Model Development}

The hazard model is often used in medicine and biology, where the focal event, failure, typically corresponds to accident, death, or recurrence of disease. For us the focal event, takeoff, although a success, corresponds to the "failure" in the hazard literature. 
Similarly, being in the introductory stage corresponds to "survival" or "success" in the hazard literature.

Because the model for international takeoff we propose includes both time-varying (such as market penetration and GDP) and time-invariant covariates (such as cultural characteristics), a fully parametric hazard model is most appropriate (Helsen and Schmittlein 1993, Kalbfleisch and Prentice 1980). In our treatment of the parametric hazard model and the derivation of the likelihood, we draw heavily upon Petersen (1986a, 1986b). Let $T$ be a nonnegative continuous random variable that denotes the duration in a state. In the presence of time-varying covariates-which we denote as $X(t)$ - the hazard function or the rate of transition from one state to another (e.g., introduction to growth) is

$$
h(t \mid X(t))=\lim _{\Delta t \rightarrow 0} P[t \leq T<t+\Delta t \mid T \geq t, X(t)] / \Delta t .
$$

Let $t_{k}$ be the duration in a state at the time when either the state is left or censoring occurs. We divide $t_{k}$ into $k$ nonoverlapping but adjacent segments of time, which need not be of the same length. Let $t_{0}=0$ and $t_{0}<t_{1}<\cdots<t_{j-1}<t_{j}<\cdots<t_{k}$. We obtain the following probability of surviving beyond duration $t_{j}$ given survival at duration $t_{j-1}$, conditional upon the path taken by $X(t)$ up to duration $t_{j}$ :

$$
\begin{aligned}
P & {\left[T \geq t_{j} \mid T \geq t_{j-1}, X\left(t_{j}\right)\right] } \\
& =\exp \left[-\int_{t_{j-1}}^{t_{j}} h\left(s \mid X\left(t_{j}\right)\right) d s\right] .
\end{aligned}
$$

The survival function for duration of $t_{k}$ can then be written as

$$
\begin{aligned}
S\left[t_{k} \mid X\left(t_{k}\right)\right]= & \prod_{j=1}^{k} P\left[T \geq t_{j} \mid T \geq t_{j-1}, X\left(t_{j}\right)\right] \\
= & \left.\exp \left[-\int_{0}^{t_{1}} h\left(s \mid X_{0}\right)\right) d s\right] \\
& * \cdots * \exp \left[-\int_{t_{k-1}}^{t_{k}} h\left(s \mid X\left(t_{k-1}\right)\right) d s\right] \\
= & \exp \left[-\sum_{j=1}^{k} \int_{t_{j-1}}^{t_{j}} h\left(s \mid X\left(t_{j-1}\right)\right) d s\right] .
\end{aligned}
$$

The probability density function becomes

$$
f\left(t_{k} \mid X\left(t_{k}\right)\right)=h\left(t_{k} \mid X\left(t_{k}\right)\right) S\left[t_{k} \mid X\left(t_{k}\right)\right] .
$$

We propose to test a log-logistic function because it allows for nonmonotonic baseline hazards. The hazard function $(h(t))$ and survival function $(S(t))$ for a logistic distribution can, in a general form, be written as

$$
\begin{aligned}
& h(t)=\frac{\lambda p(\lambda t)^{p-1}}{1+(\lambda t)^{p}}, \\
& S(t)=\frac{1}{1+(\lambda t)^{p}},
\end{aligned}
$$

where:

$$
\lambda=e^{-\beta^{\prime} x_{i}} ; p=\frac{1}{\sigma} .
$$

The log-likelihood is

$$
\ln L_{i}=\delta_{i} \ln h\left(t_{k} \mid x_{k}\right)-\sum_{j=1}^{k} \int_{t_{j-1}}^{t_{j}} h\left(s \mid x_{j}\right) d s .
$$

An interpretation of this model is that the hazard function is adjusted by the independent variables of each individual category in each country at each time period. This adjustment occurs by the hazard ratio, which is defined as $e^{-\beta}$. Positive $\beta$ coefficients decrease the probability of takeoff and negative $\beta$ coefficients increase the hazard of takeoff. The parameter $\sigma$ characterizes the distribution of the hazard rate. $\delta_{i}$ is a right-censoring indicator.

Similar to Helsen and Schmittlein (1993), but unlike Jain and Vilcassim (1991), we do not include a term for unobserved heterogeneity. We capture heterogeneity across categories and countries by including theory-based category and country variables in our model.

\section{Conceptual Framework and Hypotheses}

We develop a theory to explain takeoff around two broad groups of factors, country characteristics and category characteristics. We can further classify country characteristics into economic, cultural, and information access variables. The subsequent discussion develops specific hypotheses for each of these variables.

Economic Variables. Four economic constructs are likely to play an important role in the takeoff of new 
products: a country's wealth, economic progressiveness, economic roles in the household, and openness of the economic system.

Wealth: Prior research posits that wealth strongly influences the speed with which inhabitants of a specific country adopt a new product (Helsen et al. 1993). So we expect that wealth will have a strong effect on time-to-takeoff. A well-known conclusion of the diffusion literature is that innovators generally are wealthier than later adopters (Rogers 1995). Wealthier people attach a lower utility to money, which is what economists call the "wealth" effect. The lower utility of money has two consequences. First, wealthier people can better afford the risks of adopting a new product early (Dickerson and Gentry 1983). Risk is an important determinant of timing of adoption (Sheth 1968). Second, because prices of new products tend to start high and drop steadily (Golder and Tellis 1998), wealthier people will be able to better afford new products early when prices are high. In sum, wealthier people are expected to adopt a new product earlier than less-wealthy people. So, we hypothesize:

Hypothesis 1 (H1). New products take off faster in countries with higher average wealth than in those with less average wealth.

Economic Progressiveness: One meaning of economic progressiveness is the extent to which wealth is distributed within countries. Even when a population at large in a country has high average wealth, it may be concentrated in a few homes. In this case, the vast majority of people may still be poor and may be unable to afford the new product. Thus, after controlling for average wealth per capita, high disparity in wealth may mean that many people cannot afford a new product, causing it to take off later than when income disparity is low.

Economic progressiveness also refers to the extent to which countries participate in economic unions. Country unions facilitate the movement of capital, labor, suppliers, and goods between countries. Unions reduce economic disparity among countries and encourage the formation of a common market. This economic atmosphere is more likely to promote the dispersion and growth of new products in countries that belong to the union. Thus, sales of new products may grow more rapidly within countries that take part in such unions. This argument is also in line with the finding of Mahajan and Muller (1994), that a borderless Europe leads to faster diffusion. We hypothesize:

Hypothesis 2 (H2). New products take off faster in countries with greater economic progressiveness than in countries with lower economic progressiveness.

Economic Roles in the Household: Over the second half of the century there has been a steady change in work roles in the family. Families have moved from having predominantly one income earner to two income earners (with the woman, in addition to the man, working outside the home). Such households experience intense pressure on time, and the family has less time for housework, relaxation, and entertainment. Such families put a high value on any appliances that help them save time. All new products have at least some time-saving features. For example, dryers and washers free a great deal of time compared to manual washing and hanging clothes to dry. VCRs enable convenient watching of movies at home instead of time-consuming trips to movie theaters. Home computers save time in word processing and home accounts.

Thus, we expect that countries in which more women work outside the home are likely to adopt durables faster than those in which fewer women do so. This position is consistent with that of Gatignon et al. (1989). We hypothesize:

Hypothesis 3 (H3). New products take off faster in countries with a high activity rate of women than in countries with a low activity rate of women.

Openness of the Economic System: The openness of the economic system of a country refers to the extent to which the country is involved in international trade. Because of increasing international free trade between countries, this may be an important and increasingly relevant factor in the international takeoff of new products. Open economic systems may speed the takeoff of new products for two reasons. First, economic openness encourages the development or opening of unified infrastructure between countries, such as freeways, phone lines, railways, 
TV broadcasting, etc. Such infrastructure may facilitate the faster spread of new products through observation or word of mouth. Economic openness also fosters greater competition, which increases production and distribution efficiency (Talukdar et al. 2001). Savings from these efficiencies should make new durables more affordable to consumers, with a faster takeoff as a consequence. So, we hypothesize:

Hypothesis $4(\mathrm{H} 4)$. New products take off faster in countries that have a more open economic system than in countries that have a less open economic system.

Cultural Variables. Prior research suggests that a country's culture strongly affects the speed at which its citizens adopt a new product (Dekimpe et al. 2000, Gatignon et al. 1989, Takada and Jain 1991). We identify four cultural variables that can affect time-to-takeoff across countries: uncertainty avoidance, masculinity, ${ }^{2}$ need for achievement, and industriousness.

Uncertainty Avoidance: Uncertainty avoidance refers to the level of anxiety about the future (Hofstede 1980, 2001). Societies that are high in uncertainty avoidance continuously feel the inherent uncertainty in life as a threat that must be fought, while societies low in uncertainty avoidance more easily accept uncertainty and take "each day as it comes" (Hofstede 1980).

We expect countries that are high in uncertainty avoidance to show later takeoffs than those that are low in uncertainty avoidance, for two reasons. First, societies that are low in uncertainty avoidance are more willing to take risks. Therefore, they will more readily accept new products (Rogers 1995). Second, societies high in uncertainty avoidance consider novel ideas as dangerous and are more intolerant toward change than societies low in uncertainty avoidance (Hofstede 1980). Thus, countries that are low in uncertainty avoidance will embrace a new product more easily than countries that are higher in uncertainty avoidance.

Our expectation is also consistent with prior research. For example, Lynn and Gelb (1996) find

\footnotetext{
${ }^{2}$ We found neither theoretical support nor empirical evidence in our data to include the two other Hofstede dimensions, power disparity and individualism, as explanatory variables.
}

a negative correlation between a country's uncertainty avoidance and the penetration of six consumer durables. Steenkamp et al. (1999) find that consumers in countries high in uncertainty avoidance are less innovative than consumers in countries low in uncertainty avoidance.

Нүротнеsis 5 (H5). New products take off faster in countries low in uncertainty avoidance than in countries high in uncertainty avoidance.

Masculinity: In most cultures men tend to be more assertive, while women tend to be more nurturing. Male behavior is associated with autonomy, aggression, exhibition, and dominance, while female behavior is associated with nurturance, affiliation, and humility (Hofstede 1980, 2001). Masculinity and femininity refer to the sex role pattern in society at large, to the extent it is characterized by male or female characteristics. We expect masculinity to affect the speed of takeoff for two reasons.

First, masculine societies attach more value to recognition and wealth, while feminine societies attach more value to human contacts and living environment (Hofstede 1980). The adoption of new products allows consumers to exhibit their wealth and success, which may be more compatible with masculine societies. Consumers in masculine societies may thus show higher innovativeness, as compared to consumers in more feminine societies (Steenkamp et al. 1999).

Second, in masculine societies people tend to make decisions independently and admire the strong and the independent (Hofstede 1980). When a new product first emerges, adoptions are few and require independent decisions by innovators. This trait of masculine societies may also lead to better acceptance of new products. In contrast, in feminine societies the tendency to make group decisions may lead to less acceptance of a product. For all these reasons, we expect masculine countries to show faster takeoff than feminine countries.

So, we hypothesize the following.

Hypothesis 6 (H6). New products take off faster in countries high in masculinity than in countries low in masculinity. 
Need for Achievement: In one of the earliest discussions of need for achievement, Murray (1938) describes it as the tendency or desire to do things as rapidly and/or as well as possible. Need for achievement includes successfully and independently overcoming obstacles, competing with and surpassing others, and high self-regard. Veroff et al. (1962) associate a high need for achievement particularly with working harder, being less satisfied with current success, and being more oriented to the future fruits of work. All these traits may lend themselves to greater eagerness for adopting new products and greater willingness to experiment with new products as soon as they are available. Thus, we expect:

Hypothesis 7 (H7). New products take off faster in countries in which the inhabitants have a high need for achievement than in countries in which the inhabitants have a low need for achievement.

Industriousness: Industrious people are inclined to work and tend to value the fruits of work more than less industrious people. The industriousness of a population can affect the speed of takeoff for supply and demand reasons. Such people realize that innovations can make work more productive as well as make their rest from work more productive, so industrious people tend to be more receptive to innovations as well as to work harder to develop innovations. Thus, when a new product is available, industrious entrepreneurs, retailers, and distributors are likely to work harder to make this product available to the general population. At the same time, the people themselves are more likely to search for, try out, and adopt the new product. Thus, the new product is likely to take off faster in an industrious culture than in one that is not industrious. So we expect the following.

Нүротнеsis 8 (H8). New products take off faster in countries with a more industrious culture than in one that is less industrious.

Information Access. Prior research suggests that people's access to information strongly affects the speed at which they adopt a new product (Rogers 1995). Therefore, we may expect that a new product takes off faster in countries in which inhabitants have easy access to information than in other countries.
We identify three factors that capture different dimensions of information access: media intensity, mobility, and education.

Media Intensity: Mass media such as newspapers, radio, and television play an important role in creating awareness of a new product among potential adopters (Beal and Rogers 1960) and influencing acceptance of a new product (Katz and Lazarsfeld 1955). Mass media may also lead to greater ability of consumers to detect superior new products, and thus increase the rate at which, and the likelihood that, consumers will adopt them. Mass media also contribute to the cosmopolitanism of consumers of a country, especially if it concerns "cosmopolite channels" (Rogers 1995). Through cosmopolite channels, consumers in a target country can access information about innovations that have been introduced in other countries, even before the innovation is introduced in the target country (Gatignon et al. 1989). Such information can hasten the takeoff of the innovation in the target country. For all these reasons, we hypothesize:

Hypothesis 9 (H9). New products take off faster in countries high in media intensity than in countries low in media intensity.

Mobility: Interpersonal communication affects the rate at which consumers learn about new products. An important facilitator of such communication is mobility. Gatignon et al. (1989) have shown that the higher the mobility of a country's inhabitants, the more rapidly new products penetrate the social system. So, we hypothesize the following.

Hypothesis 10 (H10). New products take off faster in countries in which the inhabitants have high mobility than in countries in which the inhabitants have low mobility.

Education: Education involves the exposure of people to a constant stream of new ideas, which makes them more receptive to innovations. Education also sensitizes people to the importance of technology in human progress. That again makes them more receptive to innovations. Indeed, a general finding in diffusion research is that educated people tend to adopt new products earlier than noneducated people (Rogers 1995). So, we hypothesize the following. 
НyротнеSIs 11 (H11). New products take off faster in countries in which the inhabitants have enjoyed higher education than in countries in which the inhabitants have not enjoyed higher education.

\section{Category Characteristics}

We identify four category characteristics that may affect the probability of takeoff: product class, market penetration, number of prior takeoffs, and year of introduction. (Although these variables are intrinsically category characteristics, some, like market penetration, number of prior takeoffs, and introduction year, could also vary by countries.)

Product Class: Product class may affect the probability of a new product's takeoff (Gatignon et al. 1989, Golder and Tellis 1997). In particular, we distinguish between white goods, such as kitchen and laundry appliances, and brown goods, such as entertainment and information products. We expect brown goods to take off earlier than white goods because they appeal to all members of a household, provide more instant gratification, and are more visible to guests. Thus, we hypothesize:

Hypothesis 12 (H12). Brown goods take off faster than white goods.

Market Penetration: We define market penetration as the percentage of households that have purchased the new product. Prior research posits that product categories reach takeoff at an average market penetration of $2.5-3 \%$ (Golder and Tellis 1997). The diffusion literature also suggests that market penetration may be an important correlate of the event that we call takeoff (Sultan et al. 1990). Thus, an increase in market penetration increases the likelihood of a takeoff. To avoid problems of simultaneity, we include the lagged value of market penetration as an independent variable in the model. Thus, we hypothesize:

Hypothesis 13 (H13). The higher the market penetration, the higher the probability of takeoff.

Prior Takeoffs: A new product's prior takeoff in other countries can stimulate takeoff in a target country for at least four reasons. First, as the product takes off in other countries, the media are more likely to report its use or popularity, increasing its attractiveness in the target country. Second, on seeing a takeoff of a new product in other countries, manufacturers or retailers are more likely to promote sales in the target country, triggering a takeoff. Third, takeoff in other countries implies more adopters, so that a consumer in a target country has a higher probability of contacting an adopter from the other countries. Such a contact can increase acceptance of the new product and thus takeoff in the target country. Fourth, when a product takes off in other countries, potential adopters in a target country are more likely to perceive the new product to be a success. This perception is likely to reduce the perceived risk associated with adopting the new product, increasing acceptance of the new product and takeoff in the target country. Thus, we hypothesize:

Нүротнеsis 14 (H14). The higher the prior takeoffs in other countries, the higher the probability of takeoff in a target country.

Year of Introduction: The literature is ambiguous about the effect of the year of introduction. Golder and Tellis (1997) argue that due to the faster speed of technological innovation in more recent years, new products improve faster. Thus they are likely to appeal to consumers and takeoff off sooner than products introduced in prior decades. On the other hand, Bayus $(1992,1994)$ argues that technological change is not occurring any faster in more recent decades than it did in earlier decades. By this logic, takeoff should not occur any faster in more recent decades than in earlier decades. Recently, Van den Bulte (2000) showed that although on average there has been an increase in diffusion speed, this effect disappears when one controls for economic and demographic evolutions as well as the nature of products studied. Therefore, we will not posit a hypothesis for this effect, but merely include it as a control variable.

\section{Data}

This section describes our data collection and measures.

\section{Data Collection}

The data collection was difficult and slow. It took the periodic efforts of several research assistants and 
authors over four years to assemble, prepare, and analyze all the data. In searching for data, the authors had to pursue numerous leads (many of them futile), including contacting dozens of sources through hundreds of e-mails and phone calls, and traveling to various international cities.

We hoped to gather data for 10 consumer durables (refrigerator, washing machine, freezer, dishwasher, color TV, dryer, VCR, computer, CD player, and microwave oven) across 16 European countries (Austria, Belgium, Denmark, Finland, France, Germany, Greece, Ireland, Italy, the Netherlands, Norway, Portugal, Spain, Sweden, Switzerland, and the United Kingdom). In effect, we succeeded in obtaining data on 137 of these 160 country-categories, for about an $86 \%$ achievement rate.

For data on product sales, the following sources proved most valuable:

- Euromonitor.

- GFK.

- The Economist Intelligence Unit (EIU).

- TableBase of Responsive Database Services, Inc.

- Archives and publications of associations of appliance manufacturers in various European countries.

- William P. Putsis Jr., who generously sent us data on a few categories.

Some of the data series from these sources overlapped. When sources overlapped, sometimes the figures were identical and sometimes they differed. Even when figures from two sources did not match, they were highly correlated. When figures did not match, we used the figures from the source that provided (i) all observations for a series and (ii) the greater amount of overall data across series. These rules ensured that (i) a particular series was unlikely to have a sudden increase or decrease in sales, just because of a change in the source of data, and (ii) a maximum consistency existed in the underlying process that generated various series of data, given that we had to tap multiple sources. Note that the use of multiple sources increases the noise in the data, and thus would increase the probability of not finding the patterns that we expect.

To gather data on our explanatory variables, we primarily used publicly available sources because these are credited to be more reliable (Golder 2000). Our key sources of data are:

- The Statistical Yearbook of the United Nations;

- The Penn State World Table Database;

- World Bank Statistics;

- Eurostat Review;

- Individual sources, such as Parker (1997) and Hofstede (1980, 2001).

\section{Measures}

This subsection explains the measures for year of introduction, takeoff, and the independent variables in our model.

Year of Introduction. For most country-categories we have data from the year of introduction, with sales as low as 1,000 units per year. However, for a few country-categories we were unable to get the early years of data, especially during or before World War II. To avoid left-truncation bias we drop such country-categories. For most country-categories, we found that a consistent rule to include countrycategories is if first-year penetration is less than $0.5 \%$. (In addition, we dropped four countries in VCRs because sales for those countries started quite high relative to the others). By using this rule, we have year of introduction for 120 of the 137 country-categories. The average first-year sales per country (across categories) ranges from 1,000 units for smaller countries to 20,000 units for the largest one.

Takeoff. Recall that takeoff is the start of the growth stage of the life-cycle characterized by a rapid growth in sales. A heuristic to identify takeoff is very important because it provides a basis for empirical analysis as well as a simple rule that practicing managers can use. However, when the base sales are small, a relatively large percentage of growth in sales may occur without signaling takeoff. On the other hand, when the base sales are large, takeoff may occur at a relatively small percentage of growth in sales.

Therefore, Golder and Tellis (1997) defined a threshold for takeoff, which is a standard plot of growth rate versus sales by year. They defined takeoff as the first year growth crosses the threshold. They inferred the shape of the threshold so that it would give the best prediction of takeoff identified visually. The advantages of the threshold rule are that it is simple to use, 
Figure 2 Threshold for Takeoff

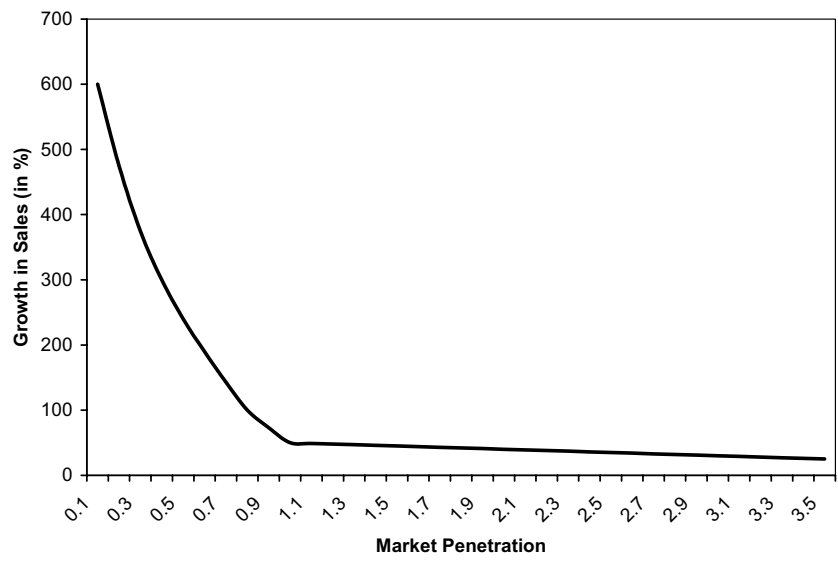

is interpersonally certifiable, and has predictive validity. That is, the rule enables one to predict the year of takeoff as it occurs, without need for all the data. However, the Golder and Tellis (1997) threshold did not easily fit our multinational application because of the great diversity of base sales across the 16 countries in our sample.

As a result, we modified the rule, using market penetration rather than sales as a base with which to evaluate growth. We define the threshold for takeoff as a standard plot of growth in sales for various levels of market penetration, as shown in Figure 2. We operationalize takeoff as the first year a product's growth in sales crosses the threshold in Figure 2. Like Golder and Tellis (1997), we inferred the shape of the threshold so that it gives the best prediction of takeoff identified visually.

This simple rule for international takeoff conforms very well with a visual inspection of the sales curve in 132 of 137 country-categories. In two countrycategories growth failed to cross the threshold albeit a takeoff occurred. In three other country-categories, we did not have enough data to determine the takeoff.

We also developed an entirely different method for defining takeoff, based on a multirater visual identification of takeoff without raters having any knowledge of the threshold rule (see Tellis et al. 2002). To ascertain the robustness of this rule, we repeated the entire descriptive and hazard analysis using the alternative method. The main results are robust to the alternate measure of takeoff.
From our identification of the introduction and takeoff, we calculated "time-to-takeoff" as the number of years between introduction and takeoff. By using this rule, we have time-to-takeoff for 117 of the 137 country-categories.

Independent Variables. We measured economic wealth by GDP per capita in thousands of U.S. dollars. We also included real GDP per capita in constant dollars, adjusted for changes in the terms of trade (we used the 1985 international prices for domestic absorption and current prices for exports and imports). This measure gave similar results.

Recall that we operationalized a country's economic progressiveness as income inequality and participation in economic unification. A well-established measure of income inequality is the GINI index. We extracted our measure of the GINI index from the database of Deininger and Squire (1996), which can be accessed on the website of the World Bank. To maximize consistency across countries, we selected the GINI coefficient based on net income (not expenditure or gross income), number of households (not population), and national coverage. We selected the GINI coefficient that was closest to 1980, to be consistent with the time of the Hofstede measures on culture.

For participation in economic unions we used a dummy, which indicates if the country was a member of the European Union (or one of its predecessors, such as the European Coal and Steel Community (ECSC) and the European Economic Community (EEC)) in a given year. The EU (then called ECSC) was founded in 1951 by Belgium, France, Germany, Italy, Luxemburg and the Netherlands. Later, Austria (1995), Denmark (1973), Finland (1995), Greece (1981), Ireland (1973), Portugal (1986), Spain (1986), Sweden (1995), and the United Kingdom (1973) all joined.

We measured a country's economic openness by its level of international trade, which encompasses the exports (fob) and imports (cif) per capita in thousands of U.S. dollars. As a composite measure for economic openness or international trade, we use the sum of exports and imports per capita in thousands of U.S. dollars.

We measured economic roles in the household through the activity rate of women, which refers to the percentage of women that are economically 
active. People that are economically active are people who have a job plus those who are unemployed but actively seeking work.

For the cultural variables of uncertainty avoidance and masculinity, we used Hofstede's measures. Readers may refer to the original work of Hofstede (1980) or its most recent edition (Hofstede 2001). Since Weber (1958), need for achievement is closely tied to religion. The major religious difference among nations in Europe is the ratio of Protestants to Catholics. There is strong evidence in sociology that Protestant religions are more supportive of a high need for achievement than is the Catholic faith (McClelland 1961, Weber 1958). Therefore, we will operationalize need for achievement by the percentage of Protestants (see Parker 1997). We use climate as a proxy for industriousness (reverse scaled). This operationalization is based on the argument that climate plays a strong role in human mood, work ethic, and productivity. A hot climate discourages hard work and leads to lethargy. On the other hand, in cold climates the need to keep warm stimulates individuals to undertake physical activity. Over time, these influences could lead to work ethics and attitude, which involve more industry and enterprise in cool climates than in warm climates. We measure climate by monthly high temperatures (max C), as inventoried by Parker (1997).

We measured media intensity through several measures. A first measure is the total circulation of newspapers-the number of newspaper copies printed-in the country, per 100 inhabitants of the country. A second measure is the number of radios (receivers) in the country, per 100 inhabitants of the country. Note that this series has the disadvantage that the UN switched definition in the 80 s from inventorying the number of licenses to an estimated number of receivers in use. A third measure is the number of TVs (receivers) in the country, per 100 inhabitants of the country. A fourth measure is the number of telephones in the country, per 100 inhabitants of the country. As a composite measure for media intensity, we use the sum of these four measures. Because in post-WWII Europe the most important mobility factor is car possession, we measure mobility by the number of cars in the country, per 100 inhabitants. For education, we use the number of third-degree (university) students as a percentage of total population.

To account for differences between brown and white goods we included the product class as a dummy variable, coded 1 for white goods and 0 for brown goods. For market penetration, we used the average possession of the product by households in the country. One of our sources provided us with the market penetration for the white goods. For brown goods, we calculated the market penetration as follows:

$$
\begin{aligned}
& \text { penetration }_{t}=\text { penetration }_{t-1} \\
& \left.\quad+\left\{\text { sales }_{\mathrm{t}}-\text { sales }_{t-r}\right) /\left(\text { number of households }_{t}\right)\right\},
\end{aligned}
$$

where " $r$ " is the average repurchase time for product in a particular category. Note that because takeoff typically occurs at a low level of penetration, adjusting the penetration to the ceiling values (Dekimpe et al. 1998) in each category is not critical.

For the number of prior takeoffs, we used two measures. First, a generic measure that counts the total prior takeoffs across all countries of Europe. The second is a region-specific measure that counts the total takeoffs in the cultural-geographic region to which a country belongs (Scandinavian, mid-European, or Mediterranean; see below). Both measures gave similar results and we report those for the second measure.

Because the variables in our model include both time-varying and time-invariant measures, we need to point out clearly which measures are of which type.

- Time-varying measures are: market penetration, number of prior takeoffs, GDP, EU membership, exports, imports, number of TVs, cars, radios, and telephones, circulation of newspapers, and education.

- Time invariant measures are: product class, introduction year, income inequality (GINI), activity rate of women, uncertainty avoidance, masculinity, percentage of Protestants, and maximum temperature.

\section{Empirical Results}

We first present some descriptive statistics, then the estimates of the model, and finally, an assessment of the model's performance. 


\section{Descriptive Statistics}

Recall that the first two goals of this study are to determine if the phenomenon of takeoff generalizes to Europe and whether there are country-specific differences in takeoff across European countries. The descriptive statistics help to answer these questions. They cover the time-to-takeoff, and the mean leads and lags in takeoff across countries.

Time-to-Takeoff. On average, new products in Europe take 6.0 years to takeoff (see Table 1A). This average is statistically different from 0 , having a standard deviation of 3.3 years. At the same time, some significant differences in this average exist across key countries and categories.

Each category has a particularly distinct time-totakeoff, which is often significantly different from other categories (Table 1A). A more dramatic, albeit related, result is the difference in time-to-takeoff between product classes (see Table 1B). As we expected, white goods (kitchen and laundry appliances) generally have a longer time-to-takeoff than

Table 1A Time-to-Takeoff by Categories

\begin{tabular}{lcrc}
\hline & & \multicolumn{2}{c}{ Time-to-Takeoff } \\
\cline { 3 - 4 } Category & Countries & Mean & Standard Deviation \\
\hline CD player & 8 & 1.8 & 1.5 \\
Color TV & 3 & 1.7 & 0.6 \\
Comp & 12 & 1.3 & 0.6 \\
Dishwasher & 14 & 8.1 & 4.5 \\
Dryers & 15 & 10.4 & 6.6 \\
Freezers & 15 & 7.7 & 5.0 \\
Micro & 16 & 10.1 & 2.5 \\
Refrigerator & 7 & 2.9 & 2.2 \\
VCRs & 12 & 3.3 & 1.8 \\
Washing machine & 15 & 4.7 & 3.2 \\
Total/average & $\mathbf{1 1 7}$ & $\mathbf{6 . 0}$ & $\mathbf{3 . 3}$ \\
\hline
\end{tabular}

Table 1B Time-to-Takeoff by Category Groups

\begin{tabular}{lccc}
\hline & & \multicolumn{2}{c}{ Time-to-Takeoff } \\
\cline { 3 - 4 } Group & Countries & Mean & Standard Deviation \\
\hline Brown goods & 35 & 2.0 & 0.4 \\
White goods & 82 & 8.2 & 2.4 \\
Overall & $\mathbf{1 1 7}$ & $\mathbf{6 . 0}$ & $\mathbf{3 . 3}$ \\
\hline
\end{tabular}

brown goods (entertainment or information products). The mean time-to-takeoff is eight years for the former, and two years for the latter-four times longer! The reason could be the greater visibility of, prestige associated with, and immediate satisfaction for, all members of a family derived from brown goods than that derived from white goods. However, other variables also affect time-to-takeoff, so we need to evaluate this result in the multivariate analysis using the hazard model.

Another categorical variable that affects takeoff is the country. Each country seems to have a distinct time-to-takeoff (see Table 2A). One of the most striking results is the dramatic difference between geographic regions of Europe (see Table 2B). Scandinavian countries (Denmark, Sweden, Norway, Finland) have the shortest time-to-takeoff. It is a

Table 2A Time-to-Takeoff by Countries Sorted by Increasing Time-toTakeoff

\begin{tabular}{lccc}
\hline & & \multicolumn{2}{c}{ Time-to-Takeoff } \\
\cline { 3 - 4 } Country & Categories & Mean & Standard Deviation \\
\hline Denmark & 9 & 3.8 & 3.3 \\
Norway & 7 & 4.0 & 2.4 \\
Sweden & 8 & 4.3 & 3.5 \\
Finland & 8 & 4.6 & 3.8 \\
Ireland & 5 & 4.8 & 4.0 \\
Belgium & 9 & 5.1 & 3.4 \\
Switzerland & 3 & 5.3 & 3.5 \\
Austria & 7 & 5.9 & 4.5 \\
Netherlands & 7 & 5.4 & 4.7 \\
Germany & 8 & 6.4 & 4.8 \\
Italy & 10 & 6.7 & 8.0 \\
Spain & 8 & 7.1 & 5.4 \\
France & 9 & 7.4 & 6.0 \\
United Kingdom & 8 & 8.5 & 7.3 \\
Greece & 5 & 9.0 & 6.8 \\
Portugal & 6 & 9.3 & 5.0 \\
Total & $\mathbf{1 1 7}$ & $\mathbf{6 . 0}$ & $\mathbf{3 . 3}$ \\
\hline
\end{tabular}

Table 2B Time-to-Takeoff by Country Group

\begin{tabular}{lccc}
\hline Region & Categories & Mean & Standard Deviation \\
\hline Scandinavian & 32 & 4.0 & 5.3 \\
Mid-West Europe & 47 & 6.0 & 4.4 \\
Mediterranean & 38 & 7.4 & 4.4 \\
Overall & $\mathbf{1 1 7}$ & $\mathbf{6 . 0}$ & $\mathbf{3 . 3}$ \\
\hline
\end{tabular}


mere 4 years (even shorter excluding Finland). This number is almost half that for Mediterranean countries (France, Greece, Italy, Portugal, and Spain), which have a mean time-to-takeoff of 7.4 years. The time for the rest of Europe (United Kingdom, Ireland, Germany, Austria, Belgium, Netherlands, and Switzerland) is in between, at 6 years. These differences are based on such a large number of different products and time periods that the results are unlikely to be due to chance.

Leads and Lags in Takeoffs. Because of the differences across categories and because categories are not evenly distributed across countries, we compute the intercountry differences in calendar year of takeoff after correcting for category differences. To do so, we first compute the mean year of takeoff for each category across all countries. We then subtract the mean of a category from each country's year of takeoff for that category. The result gives us the lead or lag time by which a product takes off in a country relative to the average in Europe. If the takeoff occurs in a country before the average, that country leads. Alternatively, that country lags. The means of these leads and lags across categories for each country are in Table 3A. Note that positive numbers imply overall leads, while negative numbers imply overall lags. The countries are listed in decreasing order of lead times.

Here again, after controlling for category differences, there is a very clear difference in leads and lags in year of takeoff across countries. Although we expected some difference across European countries, the variation, displayed in Table $3 \mathrm{~A}$, is huge. Note especially the dramatic difference in net lead/lag of 10 years between Denmark, which tops the list, and Greece, which is at the bottom. The difference in mean leads and lags in year of takeoff carries over to the differences among the country groups in Table 3B.

\section{Estimates of the Hazard Model}

Are the differences in the countries and these country groups due to economics, culture, information access or the category characteristics? Our priors were that economic variables would be the prime factor that explained intercountry differences. Cultural variables would be the next important factor. Most people with whom we discussed the study and most
Table 3A Lead and Lags in Year of Takeoff by Country Sorted by Lead Time

\begin{tabular}{lcc}
\hline Country & $\begin{array}{c}\text { Number of } \\
\text { Categories }\end{array}$ & $\begin{array}{c}\text { Mean Lead }(+) \text { or Lag }(-) \\
\text { in Takeoff (years) }\end{array}$ \\
\hline Denmark & 9 & 3.1 \\
Switzerland & 4 & 3.0 \\
Sweden & 9 & 2.8 \\
Norway & 8 & 2.1 \\
Germany & 9 & 2.3 \\
Austria & 8 & 2.0 \\
Belgium & 9 & 1.8 \\
Netherlands & 10 & 0.9 \\
Ireland & 7 & 0.7 \\
United Kingdom & 9 & 0.4 \\
Finland & 8 & -0.2 \\
France & 10 & -0.4 \\
Italy & 10 & -2.1 \\
Portugal & 7 & -3.9 \\
Spain & 9 & -4.8 \\
Greece & 6 & -8.1 \\
Total & $\mathbf{1 3 2}$ & \\
\hline
\end{tabular}

Table 3B Lead and Lags in Year of Takeoff by Country Groups

\begin{tabular}{lcc}
\hline $\begin{array}{l}\text { Country } \\
\text { Innovativeness }\end{array}$ & $\begin{array}{c}\text { Number of } \\
\text { Country-Categories }\end{array}$ & $\begin{array}{c}\text { Mean Lead }(+) \text { or Lags }(-) \\
\text { in Year of Takeoff }\end{array}$ \\
\hline Scandinavian & 34 & 2.0 \\
Mid-West Europe & 56 & 1.5 \\
Mediterranean & 42 & -3.4 \\
\hline
\end{tabular}

audiences before whom we presented also felt likewise. Subsequent empirical analysis with the hazard model enables us to test these expectations. The hazard analysis allows for multiple explanatory variables and thus is a convenient framework for such a test. We present our results in two subsections: parameter estimates and model performance.

Parameter Estimates. Table 4 contains the parameter estimates. Note that positive $\beta$ coefficients decrease the probability of takeoff and negative $\beta$ coefficients increase the probability of takeoff (as specified in Equations (5)-(7)). Because of the large number of variables and the potential for multicollinearity, we ran the model with each independent variable alone, as well as with all the independent variables together. 
TELLIS, STREMERSCH, AND YIN

The International Takeoff of New Products

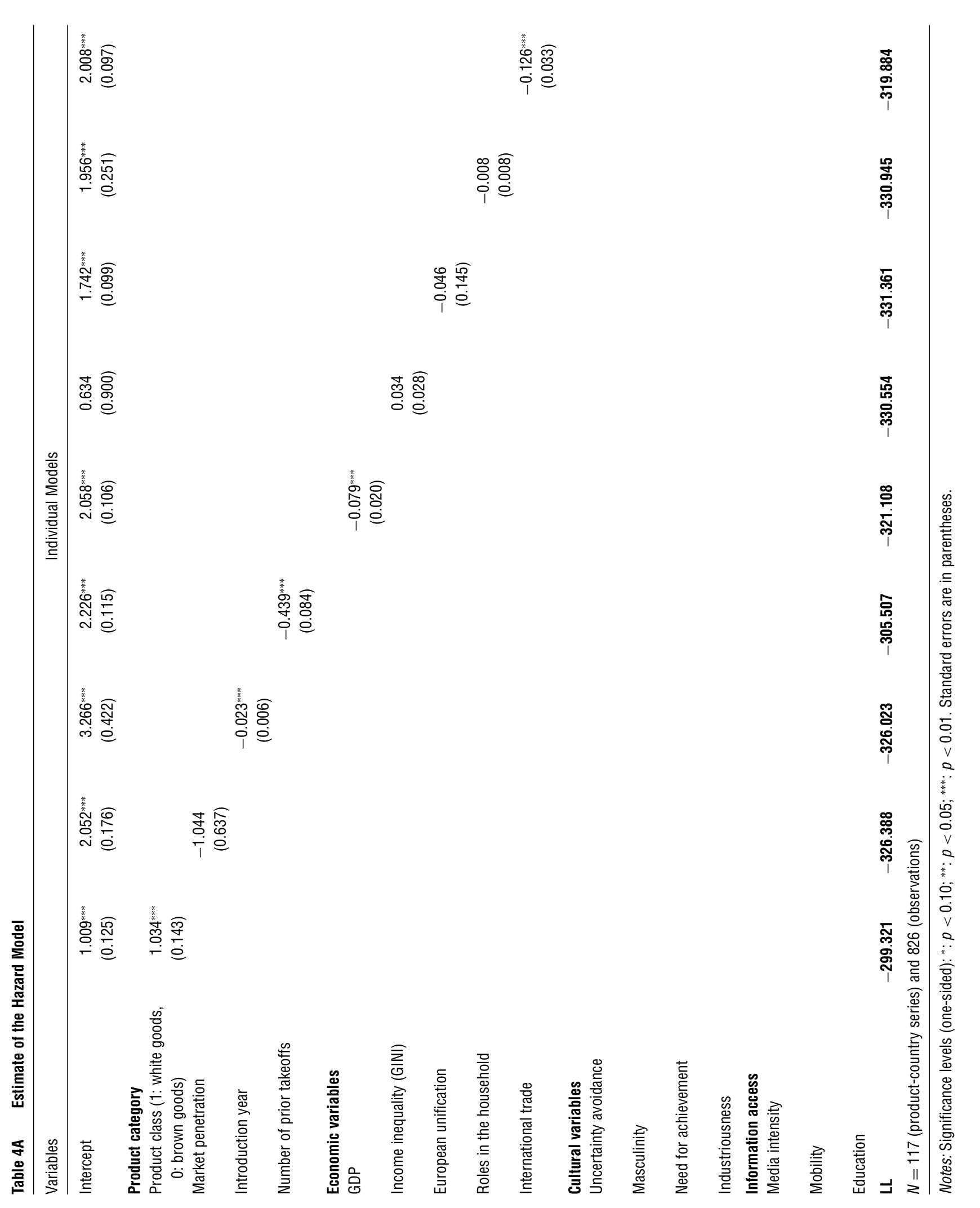




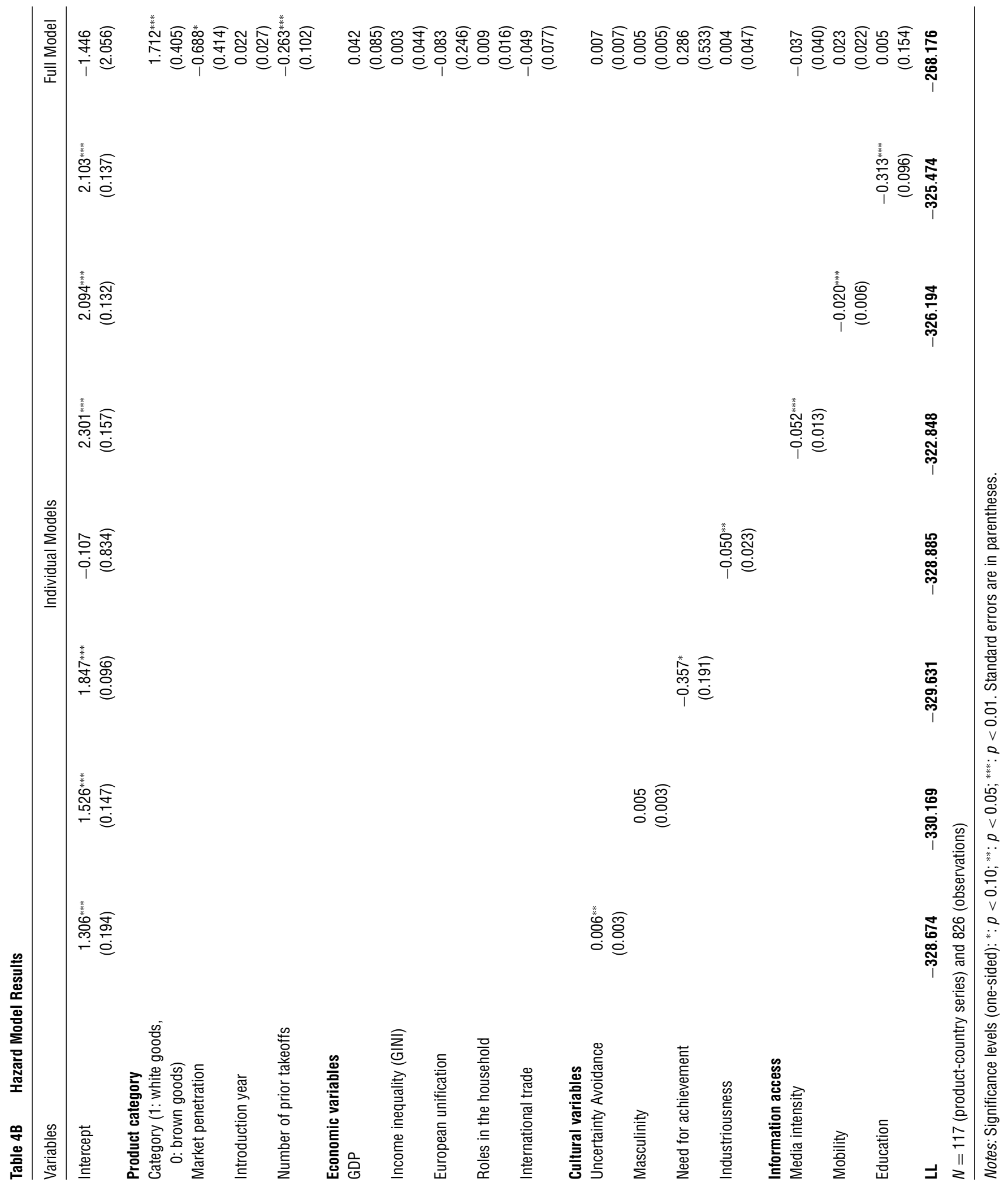


The analyses with individual independent variables show that 10 of the 14 hypothesized effects are significantly different from 0 and in the expected direction. The hypotheses not confirmed are progressiveness $(\mathrm{H} 2)$, roles in the household $(\mathrm{H} 3)$, masculinity $(\mathrm{H} 6)$, and market penetration (H13). In particular, we find that:

- Products take off faster in wealthier countries than in poorer countries (H1).

- Products take off faster in countries with more open economies, as compared to countries with lessopen economies (H4).

- Products take off faster in countries low in uncertainty avoidance, as compared to countries high in uncertainty avoidance (H5).

- Products take off faster in countries high in need for achievement, as compared to countries low in need for achievement (H7).

- Products take off faster in industrious countries, as compared to less-industrious countries (H8).

- Products take off faster in countries high in media intensity, as compared to countries low in media intensity (H9).

- Products take off faster in countries high in mobility, as compared to countries low in mobility (H10).

- Products take off faster in countries high in education, as compared to countries low in education (H11).

- The higher the prior takeoffs in other countries, the higher the probability of takeoff in a target country (H14).

- Brown goods take off faster than white goods (H12).

We also find that products that were introduced more recently took off faster. However, when we include all these variables in the full model, many of the effects are not significantly different from 0 . One reason for this result is multicollinearity. The condition index takes on a value of more than 2,200, which by far crosses the threshold of 30 (Belsley et al. 1980). Nonetheless, while all country characteristics seem susceptible to this problem, the effects of three category variables are strong, have the right sign, and are very robust to model specification: product class
(H12), lagged market penetration (H13), and prior takeoffs (H14).

To deal with the multicollinearity problem, we conducted a factor analysis to extract orthogonal, higherorder constructs. We extracted factors using principal components, which we rotated using Equamax, an orthogonal rotation method (to avoid collinearity among factors). On the basis of a scree plot, we retained three factors (explaining $71 \%$ of the variance) which we named, in order of importance:

(1) Economic wealth (43\% of variance): GDP (0.909), number of telephones (0.915), number of cars (0.885), number of TVs (0.908), exports (0.860), imports (0.854), and education (0.647) load heavily on this factor.

(2) Venturesome culture (19\% of variance): uncertainty avoidance $(-0.777)$, need for achievement (0.839), and industriousness (0.799) load heavily on this factor.

(3) Economic progressiveness ( $9 \%$ of variance): income inequality $(-0.734)$ and EU membership (0.679) load heavily on this factor.

Note that the factor analysis was unable to discriminate between economic wealth and information access as separate factors. This result may not be surprising when one considers that information access is largely dependent on the wealth of a country. We then included these factors together with the product category characteristics as independent variables in the hazard model. Table 5 presents the results of

Table 5 Results of Hazard Model with Factors

\begin{tabular}{lccc}
\hline Variables & Coefficient & $\begin{array}{c}\text { Standard } \\
\text { Error }\end{array}$ & $\begin{array}{c}\text { Change in Hazard } \\
\text { Ratio (in \%) }\end{array}$ \\
\hline Intercept & -1.327 & 1.695 & \\
Product category & $1.924^{* * *}$ & 0.453 & -85.4 \\
$\quad$ (1: white goods, & & & \\
$\quad$ 0: brown goods) & & & \\
Market penetration & $-1.172^{* *}$ & 0.521 & 222.8 \\
Introduction year & 0.038 & 0.023 & -3.7 \\
Number of & $-0.380^{* * *}$ & 0.113 & 46.2 \\
$\quad$ prior takeoffs & & & \\
Economic wealth & 0.047 & 0.164 & -4.6 \\
Venturesome culture & $-0.189^{*}$ & 0.098 & -20.8 \\
Economic & -0.065 & 0.112 & 6.7 \\
$\quad$ progressiveness & & & \\
LL & -271.31 & & \\
\hline
\end{tabular}

Notes: Significance levels (one-sided): $: p<0.10 ;{ }^{* *}: p<0.05 ;{ }^{* * *}: p<0.01$. 
this estimation. In the last column of Table 5, we also present the percentage change in the hazard ratio given a one-unit change in the independent variable. This value is equal to $100 *\left(e^{-\beta}-1\right)$ (see Equation (7)). Note that this hazard ratio cannot be straightforwardly compared across variables, because it is not unit-free.

Here, again, we find that the product characteristics are highly significant. Consistent with our hypotheses, takeoff occurs earlier for brown goods, as lagged market penetration increases, and with more prior takeoffs in neighboring countries. Counterintuitively, we now find that takeoff occurs later for more recently introduced categories. The reason for this result may be the omission of old categories from our data. We do not have data prior to 1950 . As a result, we do not have information on old categories that were introduced very early and which we suspect took a long time to takeoff. If we had these data, the effect may have been insignificant as Golder and Tellis (1997) found, or may have had a sign opposite to what we obtained.

Of the country factors we extracted, we find that only the venturesome culture $(p=0.054)$ has a significant effect on time-to-takeoff. The sign is consistent with our hypothesis, in that takeoff occurs faster in countries with a more venturesome culture. Economic wealth and economic progressiveness do not have a significant effect on time-to-takeoff. This is a surprising result, because many observers credit economics as having a predominant influence on time-to-takeoff.

\section{Performance of Hazard Model}

This section discusses the stability of the parameters, the baseline hazard, and the model's fit.

Robustness of Results: To assess the robustness of our results, we checked the sensitivity of our results to alternative distributional assumptions, unobserved heterogeneity, and the method for determining takeoff. First, to check if our distributional assumption towards the baseline hazard (logistic) affected our results, we estimated a Weibull specification of the baseline hazard. We found that it did not significantly affect our point estimates, nor did it affect the standard errors of these estimates. A Weibull hazard model is a flexible form that allows for monotonically increasing or decreasing hazards, and also nests an exponential hazard model, which has a constant hazard. The logistic specification we adopted also allows for nonmonotonic hazards.

Second, we checked if unobserved heterogeneity was a problem. We modeled unobserved heterogeneity through the often-used gamma mixing distribution. We found unobserved heterogeneity to be very weak. Also, the point estimates and standard errors we obtained in the model without heterogeneity were very close to the ones we found in a model with gamma mixing. We conclude that our model performs satisfactorily as compared to a more complex parametric hazard model with gamma mixing, and thus retain our more parsimonious specification.

Third, we stated before that we also calculated takeoff years using visual inspection to check for the validity of our findings. Using the takeoff years of this visual inspection method resulted in findings that are not significantly different from the findings we obtained through the use of our threshold rule.

In sum, we find our estimates to be very stable towards the assumed distribution of the hazard, unobserved heterogeneity, and alternative takeoff rules.

Baseline Hazard: The distribution of the hazard function is modeled through the parameter $\sigma$. For the model with the factor scores of which the results are presented in Table 5, the $\sigma$ parameter is equal to 0.37 and is significant at the 0.01 level. We display the baseline hazard function of this model in Figure 3 . Note that the $X$-axis represents time in

Figure 3 Hazard of Takeoff Using Log-Logistic Function

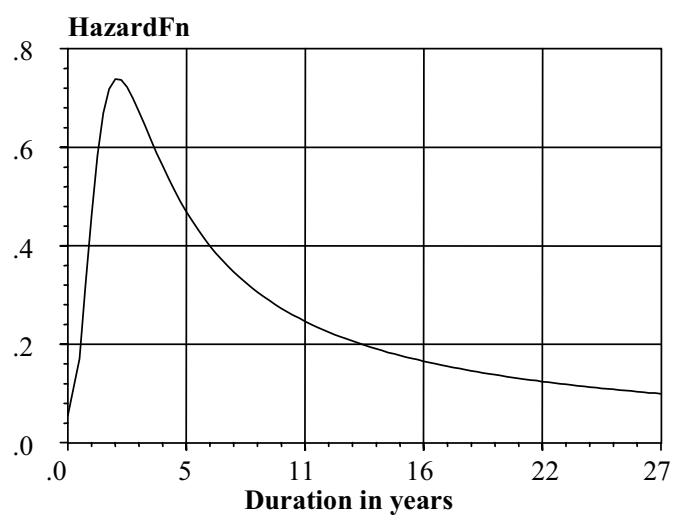

Marketing Science/Vol. 22, No. 2, Spring 2003 
years and the $Y$-axis represents the hazard function of Equation (7). This figure shows that the likelihood that takeoff will occur, given that it has not occurred yet, initially increases very rapidly to a maximum at around 3 years. After about 3 years the hazard gradually declines. In our data set, there were no products that took longer than 27 years to take off in a specific country.

Measures of Fit: To assess the model's performance, we use the likelihood ratio index (LRI, McFadden 1974). This index is a measure of how much the model reduces uncertainty and is similar to Hauser's (1978) $U^{2}$. It is analogous to the $R^{2}$ of multiple regression, although low values of LRI relative to $R^{2}$ still represent relatively good fits. A first model against which to evaluate the fit of our model is a proportional hazard model, which only includes a constant. Evaluated against this model, the model with the three factors (Table 6) has an LRI of 0.55. This value is excellent, as compared to the model proposed by Golder and Tellis (1997), who obtained an LRI of 0.31 as evaluated against this base model. We also calculated the reduction in uncertainty as compared to a loglogistic model that includes only a constant. The LRI we obtained compared to this model is 0.18. Taking into account that our null model to calculate LRI includes a constant and, most importantly, already fits a log-logistic distribution to the hazard function, we can assess this LRI as satisfactory compared to prior takeoff research in marketing (Golder and Tellis 1997).

\section{Discussion}

While the takeoff of new products is an important phenomenon, it has received limited attention, all of which focuses on the U.S. market. Because Europe has had 55 years of successful evolution of free consumer markets, that arena constitutes a good context in which to test the generalizability of takeoff. The post-World War II economic boom in Europe, together with its growing economic unification, has led to a perception among some that all of Europe has become, or is steadily becoming, one market. The takeoff of consumer durables across Europe is a suitable context in which to test the validity of that perception.
We analyzed the takeoff of 10 consumer durables across 16 Western European countries. While still limited in scope, this is one of the largest studies on international new product growth. Our analysis leads to some clear conclusions:

- Sales of most new products display a distinct takeoff in various European countries, at an average of 6 years after introduction.

- Time-to-takeoff differs dramatically across product classes. The mean time-to-takeoff is 8 years for white goods (kitchen and laundry appliances) and 2 years for brown goods (entertainment and information products).

- Time-to-takeoff differs dramatically between countries (e.g., 3.3 years for Denmark and 9.3 years for Portugal). On average, time-to-takeoff is almost half as long in Scandinavian countries (4 years) versus Mediterranean countries (7.4 years).

- Culture partly explains these differences. In particular, the probability of takeoff increases with higher need for achievement and industriousness and lower uncertainty avoidance. While economic factors individually affect the probability of takeoff in the expected direction, their effects are neither strong nor robust to model specification.

- The probability of takeoff of a new product in a target country increases with prior takeoffs in other countries.

These results have important implications for international entry and marketing of new products. The most important implication is that specific regions of Europe have distinct commonalities in terms of time-to-takeoff of new products, with sharp differences across regions. While we expected some differences, we were surprised by the size of the differences. We were also surprised by the fact that Scandinavian countries tend to have the shortest timeto-takeoff of all European countries. In contrast, the large economies of Europe, France, Germany, Italy, Spain, and the United Kingdom turned out to be less "innovative" than the Scandinavian countries. When we presented these results to audiences of managers and researchers in the United States and Europe, they were also surprised, yet found the results believable. They suspected that Scandinavian countries are relatively innovative, while Latin countries are much less so. 
A second important implication that follows from our results is the distinct advantages to a waterfall strategy over a sprinkler strategy. A waterfall strategy implies sequential introduction, while a sprinkler strategy implies simultaneous introduction of new products across countries. Our results support a waterfall strategy for three reasons. First, managers are under great pressure to pull the plug on a product that has not taken off. Thus, introducing in a few countries that are likely to show early takeoff can win internal support for continued marketing of the new product. It can help to convince critics within the company of the new product's potential and prevent the premature withdrawal of a promising new product. Past studies on diffusion have typically not emphasized this perspective, which is unique to a focus on takeoff. For example, Putsis et al. (1997, p. 354) even suggest introducing first in Germany, France, Italy, and Spain, for "seeding the diffusion process" (p. 354).

Second, takeoff in one country increases the likelihood or pressure of takeoff in other countries, as indicated by our empirical results and past research (Gatignon et al. 1989, Kalish et al. 1995). Moreover, quick takeoffs in some countries can convince distribution channels in other countries with slower takeoffs to carry the new product and support it adequately. Third, an early takeoff generates revenues and profits for the company, which it can use to improve the product, market it more aggressively, and introduce it in other international markets.

Have managers of new products adopted such a strategy in Europe? Our empirical analysis suggests not. Apparently firms do not introduce their products in different countries along their expected timeto-takeoff. This is a third important implication of our study. We arrived at this conclusion from an analysis of intercountry leads and lags in year of introduction for each category. A lead or lag in year of introduction for a target country is the difference between the mean year of introduction for a category across all countries minus the year that it was introduced in the target country. This analysis is based on only 120 country-categories because for 17 country-categories we were unable to determine the precise introduction date. We can compare the average leads or lags in
Table 6 Variation in Year of Introduction Across European Countries

\begin{tabular}{lcc}
\hline Country & $\begin{array}{c}\text { Number of } \\
\text { Categories }\end{array}$ & $\begin{array}{r}\text { Mean Lead (+) or Lags (-) } \\
\text { in Introduction (years) }\end{array}$ \\
\hline United Kingdom & 8 & 3.4 \\
Germany & 8 & 2.8 \\
France & 9 & 1.7 \\
Belgium & 10 & 1.5 \\
Denmark & 9 & 1.4 \\
Sweden & 8 & 1.2 \\
Austria & 8 & 0.8 \\
Swiss & 3 & 0.6 \\
Netherlands & 7 & -0.4 \\
Norway & 7 & -0.4 \\
Italy & 10 & -0.5 \\
Ireland & 6 & -1.1 \\
Finland & 8 & -1.6 \\
Portugal & 6 & -1.6 \\
Spain & 8 & -2.8 \\
Greece & 6 & -9.1 \\
Total & 120 & \\
\hline
\end{tabular}

year of introduction (see Table 6) to those in year of takeoff in Table 3A.

Note first that there are considerable differences in mean leads and lags in year of introduction across countries. These leads and lags do not correspond exactly to the leads and lags in year of takeoff. In particular, large, developed economies, such as the United Kingdom, Germany, and France, show early product introductions but late product takeoffs, while Scandinavian countries, such as Sweden and Norway, show relatively late product introductions and early takeoff. (Note that this effect for the Scandinavian countries occurs even after the inclusion of prior takeoffs that accounts for potential spillover due to takeoff in other countries.) This difference could occur for several reasons.

First, managers of new products may not be aware of these results and may not have analyzed the success of past introductions along these lines. Second, managers of new products may be introducing products in economically advanced countries, assuming that these countries are likely to see quick product takeoffs. If so, our results are the opposite. Third, managers of new products may be focusing purely on sales, and not on the profits or signaling value that accrue from an early takeoff. 
A fourth implication of our study is that managers can use the takeoff of products in one country to predict takeoff in other countries. For this purpose, the hazard model is useful and convenient. Even without using the model, managers can use the consistent intercountry differences in takeoff as a heuristic to gauge the likelihood and timing of takeoff in other countries. Similarly, public policy makers can use the results of the study to ascertain the time and likelihood of takeoff of a new product in their own country, given its performance in other countries. Such a determination may play a role in encouraging or supporting investments in production and marketing so as to encourage timely local manufacturing of new products.

This study has many obvious limitations, some of which we need to mention. First, we were unable to obtain data before 1950. Thus, we had to drop categories if they were introduced in a country before 1950. This problem especially affected refrigerators. The mean time-to-takeoff may have been longer for refrigerators (2.9 years) if data for this category in all countries were included. Fortunately, this omission biases one of our results in the direction opposite to our major findings and hypotheses. If we had all the data, we would probably find that takeoff time is longer for white goods than we presently find.

Second, we were unable to get consistent measures of price and distribution in all the categories and countries. We were thus unable to assess the role of important variables that managers can control to trigger takeoff.

Third, we did not include U.S. data. In many cases, the products in our sample may have taken off in the United States before they did so in any European country. It would be interesting to compare and relate the takeoff in Europe with that in the United States or other North American countries.

Fourth, our measures of cultural differences may not directly assess peoples' readiness to adopt new products (e.g., Parsuraman 2000). However, until such measures are available, the intercountry timeto-takeoff itself could serve as a surrogate of the innovativeness of countries.

Despite these limitations, we hope that researchers and academics will find value in these findings.
We trust our effort will stimulate further research to overcome these limitations.

\section{Acknowledgments}

The authors gratefully acknowledge the comments of Delane Botelho, Peter Golder, Geert Hofstede, Joseph Johnson, Ashish Sood, Jan-Benedict Steenkamp, and participants at seminars in the marketing departments of the University of Washington, University of Iowa, University of Miami, University of Texas, University of Southern California, and Erasmus University Rotterdam. The authors also thank William Putsis, Jr. for sharing some of his data. Finally, they thank CIBEAR (USC) and the Marketing Science Institute for financial support.

\section{References}

Agarwal, R., Barry L. Bayus. 2002. The market evolution and sales take-off of product innovations. Management Sci. 48(8) 1024-1041.

Bayus, Barry L. 1992. Have diffusion rates been accelerating over time? Marketing Lett. 3(July) 215-226.

. 1994. Are product life cycles really getting shorter? J. Product Innovation Management 11(4) 300-308.

Beal, George M., Everett M. Rogers. 1960. The adoption of two farm practices in a central Iowa community: Ames, Iowa agricultural and home economics experiment station. Special Rep. 26.

Belsley, D., E. Kuh, R. E. Welsh. 1980. Regression Diagnostics. John Wiley \& Sons, Inc, New York.

Deininger, Klaus, Lyn Squire. 1996. Measuring income inequality: A new database. Available at http://www.worldbank.org/research/ growth/dddeisqu.htm.

Dekimpe, Marnik G., Philip M. Parker, Miklos Sarvary. 1998. Staged estimation of international diffusion models: An application to global cellular telephone adoption. Tech. Forecasting and Soc. Change 57 105-132.

- - - -2000 . Global diffusion of technological innovations: A coupled hazard approach. J. Marketing Res. 37(February) 47-59.

Dickerson, Mary Dee, James W. Gentry. 1983. Characteristics of adopters and nonadopters of home computers. J. Consumer Res. 10 225-235.

Ganesh, Jaishankar, V. Kumar, Velavan Subramaniam. 1997. Learning effect in multinational diffusion of consumer durables: An exploratory investigation. J. Acad. Marketing Sci. 25(3) 214-228.

Gatignon, Hubert, Jehoshua Eliashberg, Thomas S. Robertson. 1989. Modeling multinational diffusion patterns: An efficient methodology. Marketing Sci. 8(3) 231-247.

Golder, Peter N. 2000. Historical method in marketing research with new evidence on long-term market share stability. J. Marketing Res. 37(2) 156-172.

, Gerard J. Tellis. 1997. Will it ever fly? Modeling the takeoff of really new consumer durables. Marketing Sci. 16(3) 256-270. 

growth of new consumer durables. J. Forecasting 17 259-280.

Hauser, John. 1978. Testing the accuracy, usefulness, and significance of probabilistic choice models: An information theoretic approach. Oper. Res. 26(May) 406-421.

Heeler, Roger M., Thomas P. Hustad. 1980. Problems in predicting new product growth for consumer durables. Management Sci. 10(October) 1007-1020.

Helsen, Kristiaan, David C. Schmittlein. 1993. Analyzing duration times in marketing research. Marketing Sci. 12(4) 395-410.

_ Kamel Jedidi, Wayne S. DeSarbo. 1993. A new approach to country segmentation utilizing multinational diffusion patterns. J. Marketing 57(October) 60-71.

- 2001. Culture's Consequences, 2nd ed. Sage, Beverly Hills, CA.

Hofstede, Geert. 1980. Culture's Consequences. Sage, Beverly Hills, CA, 183.

Jain, Dipak C., Naufel J. Vilcassim. 1991. Investigating household purchase timing decisions: A conditional hazard function approach. Marketing Sci. 10(1) 1-23.

Kalbfleisch, J. D., R. L. Prentice. 1980. The Statistical Analysis of Failure Time Data. John Wiley \& Sons, New York.

Kalish, Shlomo, Vijay Mahajan, Eitan Muller. 1995. Waterfall and sprinkler new-product strategies in competitive global markets. Internat. J. Res. in Marketing 12 105-119.

Katz, Elihu, Paul F. Lazarsfeld. 1955. Personal Influence: The Part Played by People in the Flow of Mass Communications. The Free Press, New York.

Lynn, Michael, Betsy D. Gelb. 1996. Identifying innovative national markets for technical consumer goods. Internat. Marketing Rev. 13(December) 43-57.

Mahajan, Vijay, Eitan Muller. 1994. Innovation diffusion in a borderless global market: Will the 1992 unification of the European community accelerate diffusion of new ideas, products, and technologies? Tech. Forecasting and Soc. Change 45 221-235.

_ _ _ Frank M. Bass. 1990. New product diffusion models in marketing: A review and directions for research. Journal of Marketing 54(January) 1-26.

McClelland, D. C. 1961. The Achieving Society. The Free Press, New York.

McFadden, Daniel. 1974. The measurement of urban travel demand. J. Public Econom. 3 303-328.

Murray, H. A. 1938. Explorations in Personality. Oxford, New York.

Parker, Philip M. 1997. National Cultures of the World: A Statistical Reference. Greenwood Press, Westport, CT.
Parsuraman, A. 2000. The technology readiness index (TRI). J. Service Res. 2(4) 307-320.

Petersen, Trond. 1986a. Fitting parametric survival models with time-dependent covariates. J. Roy. Statist. Soc. C 35(3) 281-288. . 1986b. Estimating fully parametric hazard rate models with time-dependent covariates. Sociological Methods and Res. 14 219-246.

Putsis, William P., Jr., Sridhar Balasubramaniam, Edward H. Kaplan, Subrata K. Sen. 1997. Mixing behavior in cross-country diffusion. Marketing Sci. 16(4) 354-369.

_, Subrata K. Sen. 2001. International marketing and crosscountry influences. Presentation, Marketing Science Conference. Wiesbaden, Germany.

Rogers, Everett M. 1995. Diffusion of Innovations, 4th ed. The Free Press, New York.

Sheth, Jagdish. 1968. Perceived risk and the diffusion of innovations. J. Arndt, ed. Insights in Consumer Behavior. Allyn and Bacon, Boston, MA.

Steenkamp, Jan-Benedict E. M., Frenkel Ter Hofstede, Michel Wedel. 1999. A cross-national investigation into the individual and national cultural antecedents of consumer innovativeness. J. Marketing 63(April) 55-69.

Sultan, Fareena, John U. Farley, Donald R. Lehmann. 1990. A metaanalysis of applications of diffusion models. J. Marketing Res. 27(February) 70-77.

Takada, Hirokazu, Dipak C. Jain. 1991. Cross-national analysis of diffusion of consumer durable goods in Pacific Rim countries. J. Marketing 55(April) 48-54.

Talukdar, Debu, Karunakaran Sudhir, Andrew Ainslie. 2001. Identifying similarities in diffusion patterns across countries and products: A Bayesian variance components approach. Marketing Sci. 21(1) 97-114.

Tellis, Gerard J., Stefan Stremersch, Eden Yin. 2002. The international takeoff of new products: Economics, culture, and country innovativeness. Working paper, Report No. 02-121. Marketing Science Institute.

Van den Bulte, Christophe. 2000. New product diffusion acceleration: Measurement and analysis. Marketing Sci. 19(4) 366-380.

Veroff, J., S. Feld, G. Gurin. 1962. Achievement, motivation and religious background. Amer. Sociological Rev. 27 205-217.

Weber, Max. 1958. The Protestant Ethic and the Spirit of Capitalism. Charles Scribner's Sons, New York.

This paper was received October 15, 2001, and was with the authors 4 months for 2 revisions; processed by Gary L. Lilien. 